\title{
橡胶林下益智光合特性的季节动态变化
}

\author{
程汉亭 李勤奋 刘景坤 严廷良张俏燕 王进闯“
}

中国热带农业科学院环境与植物保护研究所/农业部儋州农业环境科学观测实验站, 海口 571101

\begin{abstract}
摘 要 利用农林复合模式发展生态农业可提高资源利用效率, 橡胶(Hevea brasiliensis)-益智(Alpinia oxyphylla)间作模式是 橡胶园最主要的农林复合模式。该研究通过野外原位定位实验, 研究不同季节橡胶林下环境因子对益智光合作用的影响, 并 进一步分析益智光合作用与主要环境因子的关系。结果表明: (1) 3月益智净光合速率日变化为“V”形曲线, 14:00降到最低值; 而6月、9月和 12 月益智净光合速率日变化趋势为 $10: 00$ 达到最大值, 随后缓慢降低; 在雨季 $(6$ 月和 9 月)蒸腾速率的日平均值和 日最高值均显著高于旱季( 3 月和 12 月)。表明林下益智在不同季节均能维持植株正常生长, 且表现出了较强的适应能力。3 月 土壤水分亏缺造成益智叶片气孔导度降低, 使其净光合速率维持在较低的水平。(2)通过光响应曲线修正模型计算出益智叶片 各光合响应参数, 发现 3 月最大净光合效率和光饱和点显著低于 6 月、 9 月和 12 月; 而光补偿点和暗呼吸速率却显著高于 6 月、 9 月和12月, 表明3月土壤水分亏缺导致益智光合酶活性降低, 而表现出光抑制现象, 同时呼吸强度加剧, 光合能力显著下降。 (3)采取相关分析发现, 3 月气温与净光合速率显著负相关, 空气湿度与净光合速率显著正相关, 高温和低湿度共同限制了益 智的光合作用; 而9月和 12 月, 林下光合有效辐射是益智光合作用的限制因子。
\end{abstract}

关键词 光合特性; 环境因子; 益智; 季节变化; 光合日变化

程汉亭, 李勤奋, 刘景坤, 严廷良, 张俏燕, 王进闯 (2018). 橡胶林下益智光合特性的季节动态变化. 植物生态学报, 42, 585-594. DOI: 10.17521/cjpe.2018.0016

\section{Seasonal changes of photosynthetic characteristics of Alpinia oxyphylla growing under Hevea brasiliensis}

CHENG Han-Ting, LI Qin-Fen, LIU Jing-Kun, YAN Ting-Liang, ZHANG Qiao-Yan, and WANG Jin-Chuang*

Environment and Plant Protection Institute, Chinese Academy of Tropical Agricultural Sciences/Danzhou Scientific Observing and Experimental Station of Agro-Environment, Ministry of Agriculture of the People's Republic of China, Haikou 571101, China

\begin{abstract}
Aims The development of ecological agriculture by agroforestry models could improve resource utilization. The Hevea brasiliensis-Alpinia oxyphylla agroforestry system is among the largest agroforestry models in rubber plantation. In this study, we aimed to investigate the physiological strategies that allow Alpinia oxyphylla, a perennial herb widespread under-growing the Hevea brasiliensis, to cope successfully with the environmental factors with the seasonal changes of the tropical monsoon climate.
\end{abstract}

Methods Gas exchange and light response curve measurements as well as pigment content determinations were performed periodically throughout different seasons on A. oxyphylla growing in the rubber plantation by a portable leaf gas exchange system (LI-6400).

Important findings (1) The diurnal change of the net photosynthetic rate had a V-shaped pattern in March, which decreased to be the lowest at 14:00. The diurnal changes of the $P_{\mathrm{n}}$ in June, September, and December increased to the peak at 10:00 and then began to decline slowly. The daily average and maximum of the net photosynthetic rate during the monsoon season (June and September) were much higher than those in the dry season (March and December), which suggested that $A$. oxyphylla had the physiological strategy to environmental changes in different seasons. The severe soil moisture deficit inhibits photosynthetic $\mathrm{CO}_{2}$ assimilation due to the decline of stomatal conductance in March. (2) The light compensation point and dark respiration rate of March generally were higher than those of other seasons (June, September and December), but the maximum net photosynthetic rate and light saturation point were on the contrary. The discrepancies that may be related to the photosynthetic enzymatic activity were restrained by the dry conditions, which caused the occurrence of photoinhibition,

收稿日期Received: 2018-01-12 接受日期Accepted: 2018-04-08

* 通信作者Corresponding author (jinchuangwang@yahoo.com) 
the increased respiration, and decreased photosynthetic capacity. (3) The net photosynthetic rate in March was negatively correlated with air temperature, but positively correlated with air humidity. Air temperature and air humidity in combination inhibited photosynthesis of A. oxyphylla in March. However, photosynthetic active radiation was a pivotal factor to photosynthesis of A. oxyphylla in September and December.

Key words photosynthetic characteristics; environmental factor; Alpinia oxyphylla; seasonal change; diurnal change of photosynthesis

Cheng HT, Li QF, Liu JK, Yan TL, Zhang QY, Wang JC (2018). Seasonal changes of photosynthetic characteristics of Alpinia oxyphylla growing under Hevea brasiliensis. Chinese Journal of Plant Ecology, 42, 585-594. DOI: 10.17521/cjpe.2018.0016

利用农林复合模式发展生态农业不仅可提高养 分吸收利用效率、减缓水土流失、维持局部小气候 稳定性、提高生物多样性、增加碳储量, 而且能充 分利用水肥光热资源、提高系统生产力(张斌和张桃 林, 1997; Nair \& Graetz, 2004; Mcneely \& Schroth, 2006; Dossa et al., 2008)。橡胶(Hevea brasiliensis)益智(Alpinia oxyphylla)间作模式是中国海南推广和 种植面积最大的农林复合模式, 也是橡胶种植户脱 贫致富的有效方法(Ogwuche et al., 2012), 具有较好 的经济效益和生态效益(程汉亭等, 2015)。益智为姜 科山姜属(Alpinia)多年生常绿草本植物, 主要分布 在中国的海南、广东、广西, 近年来云南、福建亦 有少量试种; 生于或栽培于林下阴湿处(程汉亭等, 2017), 是我国重点发展的“四大南药”之一，也是海 南特有的药用植物。

光合作用固定 $\mathrm{CO}_{2}$ 是植物物质生产的基础, 也 是全球碳循环的重要环节(Tuittila et al., 2004)。植物 的光合速率不仅受环境因子的影响, 还与植物本身 的生理生态特性密切相关。对气体交换的研究有利 于深入了解林下植物的光合活性和生产力, 特别是 旱季土壤水分胁迫对植物碳同化和水分利用效率的 影响(Muthuri et al., 2009)。同时, 了解气体交换的季 节变化特征有助于改进对林下植物水分需求的有效 管理。热带地区雨/旱季分明, 橡胶林土壤水分(祁栋 灵等, 2017)、林下光合有效辐射(PAR)(吴志祥等, 2013)、橡胶树物候期(陈小敏等, 2016)呈季节性变化, 这些因素必然会影响林下植物的生长和光合作用。 目前国内外学者已经开展了一些环境因子对橡胶林 下植物生长和光合特性的研究。沈守艮和郑征(2008) 研究了西双版纳橡胶-茶农林复合系统中耐阴植物 普洱茶(Camellia assamica)的光合特性, 发现林下 $P A R$ 是引起林下茶树光合差异的主要因素, 橡胶林 下 $P A R$ 的增强提高了茶树光合产物的积累。在橡胶小粒咖啡(Coffea arabica)农林复合系统里, Righi等 (2007, 2008)分别研究了不同光照和水分梯度下咖
啡树的生长状况, 获得了林下咖啡树生长的最佳光 照和水分条件。Righi等 (2008) 发现橡胶-菜豆 (Phaseolus vulgaris)农林复合系统林下可利用PAR 量是菜豆维持正常生长和产量的必要保障。然而, 环境因子对橡胶林下益智光合作用的研究却鲜有报 道，特别是益智光合作用的季节特征如何?不同时 间尺度下其光合作用主要受到哪些环境因子的制约? 对这些问题尚缺乏系统深入的认识。

本研究通过野外定位实验，分析不同季节橡胶 林下 $P A R$ 、温度、湿度和 $\mathrm{CO}_{2}$ 浓度等因子对益智光 合作用的影响, 研究益智叶片光合碳同化过程对林 下环境季节变化的生理响应机制, 揭示益智光合碳 同化对橡胶林下小气候季节性变化的适应策略, 为 进一步提出橡胶-益智农林复合系统的科学管理措 施提供理论依据。

\section{1 材料和方法}

\section{1 样地概况}

实验选择在海南省白沙黎族自治县阜龙乡天堂 村人工种植的橡胶林 $\left(109.47^{\circ} \mathrm{E}, 19.38^{\circ} \mathrm{N}\right.$, 海拔 $780 \mathrm{~m})$ 。所选的实验样地中橡胶树树龄 13 年, 平均 胸径 $18.3 \mathrm{~cm}$, 树冠平均高度约 $11 \mathrm{~m}$, 平均冠幅 $7 \mathrm{~m}$, 盖度 $80 \%-85 \%$, 橡胶树株行距 $3 \mathrm{~m} \times 6 \mathrm{~m}$; 橡胶树6 $\mathrm{m}$ 的宽行里间作 1 行益智, 益智株距 $1.5 \mathrm{~m}$, 种植时 间约6年, 株高1.5-1.8 m。

实验样地所在区域属于典型的热带季风气候, 终年高温, 雨/旱季明显, 降水集中在雨季, 且降水 量大(图1)。从2016年1月至2016年12月, 海南白沙黎 族自治县天堂村实验样地气温变幅为4.7-40.9 ${ }^{\circ} \mathrm{C}$, 最低气温出现在 2016 年的 1 月, 最高气温出现在 2016 年的 3 月和 4 月; 月平均最低气温出现在 2 月, 最高气温出现在6月(图1A)。实验样地 $P A R$ 季节变化 如图1B所示, $P A R$ 季节性差异明显, 1月最低, 平均为 $621 \mu \mathrm{mol} \cdot \mathrm{m}^{-2} \cdot \mathrm{s}^{-1}$, 7月最高, 平均值为 $1436 \mu \mathrm{mol}$. $\mathrm{m}^{-2} \cdot \mathrm{s}^{-1}$ 。全年降水量表现为1-4月、11和12月的月降

www.plant-ecology.com 

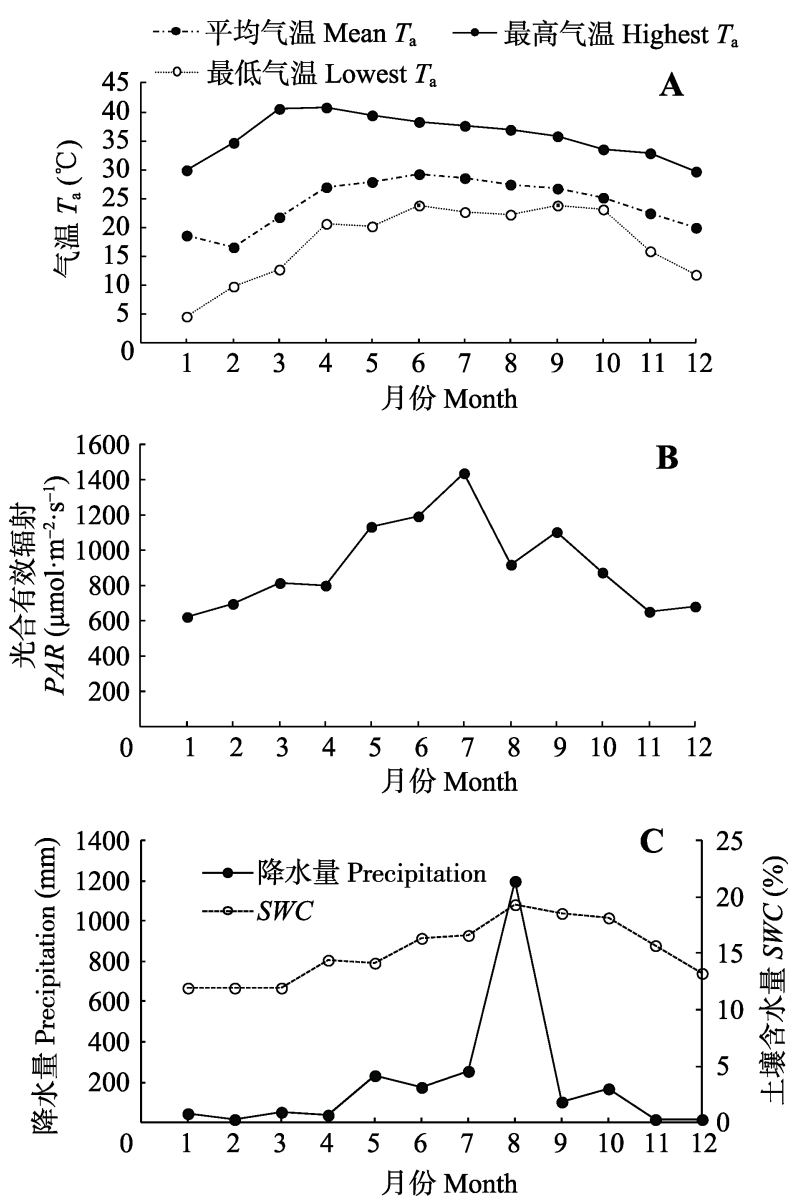

图1 气温、光合有效辐射、降水和橡胶林下土壤含水量的 季节变化。

Fig. 1 Seasonal changes of air temperature $\left(T_{\mathrm{a}}\right)$, photosynthetic active radiation $(P A R)$, precipitation and soil water content $(S W C)$ under the Hevea brasiliensis forest.

水量均低于 $54 \mathrm{~mm}$, 其中 2 月、 11 月和 12 月降水量最 低, 分别为 $15.8 、 11.6$ 和 $12.0 \mathrm{~mm} ; 5-10$ 月降水充沛, 月降水量均高于 $100 \mathrm{~mm}$, 其中 8 月降水量高达 $1201.2 \mathrm{~mm}$ (图1C)。土壤含水量月变化趋势与降水 量的趋势一致，1-3月土壤含水量低，分别为 $11.98 \% 、 11.97 \% 、 12.00 \%$, 此时土壤属于轻度干早 状态；6-9月土壤潮湿，其含水量均高于 $16.35 \%$, 其 中 8 月土壤含水量最高, 为 $19.32 \%$ (图1C)。

\section{2 研究方法}

在自然条件下, 选择长势均匀的益智植株, 并 选取生长良好无病虫害的益智功能叶片(枝条顶部 向下数第3或第4片发育完全的新生叶片)进行光合 参数的测定。在 2016 年3月、6月、9月和12月中旬选 择连续晴天无云的天气, 用LI-6400便携式光合测 量系统(LI-COR, Lincoln, USA)测量益智叶片的光 合日变化、光响应曲线, 每个参数测定 3 片功能叶, 即3次重复。

\subsection{1 光合日变化测定}

每间隔 $2 \mathrm{~h}$ (在8:00、10:00、12:00、14:00、16:00、 18:00)测定益智功能叶片的气体交换参数, 测定参 数包括净光合速率 $\left(P_{\mathrm{n}}\right)$ 、气孔导度 $\left(G_{\mathrm{s}}\right)$ 、胞间 $\mathrm{CO}_{2}$ 浓 度 $\left(C_{\mathrm{i}}\right)$ 、叶片 $P A R$ 、蒸腾速率 $\left(T_{\mathrm{r}}\right)$ 、环境 $\mathrm{CO}_{2}$ 浓度 $\left(C_{\mathrm{a}}\right)$ 、 空气湿度 $(R H)$ 、气温 $\left(T_{\mathrm{a}}\right)$ 等, 并据此计算气孔限制值 $\left(L_{\mathrm{s}}\right)=1-C_{\mathrm{i}} / C_{\mathrm{a}}$ 、瞬时水分利用效率 $(W U E)=P_{\mathrm{n}} / T_{\mathrm{r}}$ 。 叶室温度 $\left(T_{\text {leaf }}\right)$ 和叶室内空气湿度 $(R H)$ 为环境温湿 度, 叶室光强为林下光合有效辐射 $(P A R)$, 气体流速 $500 \mu \mathrm{mol} \cdot \mathrm{s}^{-1}$, 叶室 $\mathrm{CO}_{2}$ 浓度为环境 $\mathrm{CO}_{2}$ 浓度 $\left(C_{\mathrm{a}}\right)$ $\left(380-420 \mu \mathrm{mol} \cdot \mathrm{mol}^{-1}\right)$ 。

\subsection{2 光响应曲线测定}

在9:00-11:00进行光响应曲线的测定。光响应 曲线的测定用LI-6400-02B红蓝光源设定叶室中 $P A R$ 强度分别为: $1500 、 1200 、 1000 、 800 、 600 、 400$ 、 200、150、120、90、60、30、0 $\mu \mathrm{mol} \cdot \mathrm{m}^{-2} \cdot \mathrm{s}^{-1}$, 叶室 温度和湿度为环境温湿度, 气体流速 $500 \mu \mathrm{mol} \cdot \mathrm{s}^{-1}$, 测定前对叶片在饱和光强 $800 \mu \mathrm{mol} \cdot \mathrm{m}^{-2} \cdot \mathrm{s}^{-1}$ 下诱导 $30 \mathrm{~min}$ 。每个光强下测定时间为 $3 \mathrm{~min}$, 整个程序需 要约 $40 \mathrm{~min}$ 。以 $P_{\mathrm{n}}$ 为纵坐标、 $P A R$ 为横坐标做曲线, 并根据叶子飘的直角双曲线修正模型 $(Y e, 2007)$ 拟 合数据得到最大净光合速率 $\left(P_{\mathrm{nmax}}\right)$ 、光饱和点 $\left(I_{\mathrm{s}}\right)$ 、 光补偿点 $\left(I_{\mathrm{c}}\right)$ 、暗呼吸速率 $\left(R_{\mathrm{d}}\right)$ 和表观量子效率 $(A Q E)$ 。

\subsection{3 叶绿素组分测定}

摘取测量完光合作用的功能叶片(枝条顶部向 下数第 3 或第 4 片发育完全的新生叶片)用锡箔纸密 封并带回实验室液氮低温保存 $\left(-80{ }^{\circ} \mathrm{C}\right)$ 。在室温 $(25$ $\left.{ }^{\circ} \mathrm{C}\right)$ 条件下进行叶绿素提取实验。为保证益智叶片叶 绿素活性, 实验前将叶片从低温下取出, 室温条件 下放置半小时。用直径 $1.5 \mathrm{~cm}$ 的打孔器在益智叶片 上避开主叶脉打下 10 个叶圆片, 按Lichtenthaler和 Wellburn (1983)的方法测定叶绿素和类胡夢卜素的 含量。

\subsection{4 土壤含水量测定}

在距离益智植株 $50 \mathrm{~cm}$ 处, 利用土钻取 $0-10 \mathrm{~cm}$ 土样, 共选 3 个样本, 每个样本 3 个重复。利用烘干法 $\left(105{ }^{\circ} \mathrm{C}\right)$ 测定土壤含水量。

\subsection{5 比叶质量测定}

用直径 $1.5 \mathrm{~cm}$ 的打孔器在益智功能叶片(枝条 顶部向下数第 3 或第 4 片发育完全的新生叶片)上避 开主叶脉打下 30 个叶圆片, 在 $70{ }^{\circ} \mathrm{C}$ 条件下烘 $24 \mathrm{~h}$ 至 
恒质量, 用电子天平 $($ 精度为 $0.0001 \mathrm{~g}$ )称质量, 然后 计算比叶质量 $(L M A)=$ 叶片干质量/叶面积 $\left(\mathrm{g} \cdot \mathrm{m}^{-2}\right)$ 。

\section{3 数据处理}

获得的数据采用Excel 2007进行处理和图表绘 制, 采用DPS 7.55软件进行单因素方差分析, 多重 比较用最小显著差异法。相关性分析采用Pearson双 侧显著检验。

\section{2 结果和分析}

\section{1 不同季节环境因子日变化特征}

橡胶林下 $P A R 、 T_{\mathrm{a}}$ 和 $R H$ 日变化见图2。

不同季节橡胶林下环境因子 $P A R$ 均呈单峰型曲 线, 最大值出现在 12:00-14:00, 最小值均出现在监 测时段的8:00和18:00 (图2A), 这与太阳辐射一致。 因为橡胶林冠的遮挡, 林下 $P A R$ 还与橡胶树叶物候 期的生长发育和太阳年辐射规律密切相关。

不同季节 $T_{\mathrm{a}}$ 随着 $P A R$ 的增强而逐渐升高, 在 14:00达到最高值, 而在 16:00 以后随着PAR的减小 而下降(图2B)。其中 6 月和 9 月 $T_{\mathrm{a}}$ 日变化趋势一致, 10:00-16:00时段 $T_{\mathrm{a}}$ 无显著差异; 3 月在14:00-16:00时 段 $T_{\mathrm{a}}$ 峰值显著高于 6 月、9月和 12 月, $T_{\mathrm{a}}$ 高达 $40.06{ }^{\circ} \mathrm{C}$, 这是由于 3 月出现了短暂的极端高温天气造成的; 12 月的一天中各时段的 $T_{\mathrm{a}}$ 均低于 6 月、9月和 12 月, 最高气温仅为 $27.53{ }^{\circ} \mathrm{C}$ 。

不同季节 $R H$ 均表现为早晨较高, 随着 $P A R$ 和 $T_{\mathrm{a}}$ 的增高而下降, 14:00降到最低值, 随后又缓慢升 高。6月、9月和 12 月的 $R H$ 日变化趋势比较相似; 3 月 $R H$ 在 10:00-14:00降幅显著大于6月、9月和12月, 14:00 RH仅为 $30.57 \%$ ，降幅达 $58.66 \%$ (图2C)。

\section{2 不同季节益智气体交换参数日变化特征}

不同季节中随着一天中 $P A R 、 T_{\mathrm{a}}$ 和 $R H$ 的变化, 益智叶片气体交换参数 $P_{\mathrm{n}} 、 C_{\mathrm{i}} 、 G_{\mathrm{s}} 、 L_{\mathrm{S}} 、 T_{\mathrm{r}}$ 和 $W U E$ 也呈规律性的变化(图3)。

\subsection{1 净光合速率和胞间 $\mathrm{CO}_{2}$ 浓度}

图3表明益智 $P_{\mathrm{n}}$ 在不同季节日变化趋势也不同, 6月和 12 月 $P_{\mathrm{n}}$ 在 $10: 00$ 达到最大值, 随后缓慢降低, 而9月 $P_{\mathrm{n}}$ 在 $10: 00$ 和 $14: 00$ 出现双峰现象; 最高值出现 在 $14: 00$, 为 $9.19 \mu \mathrm{mol} \cdot \mathrm{m}^{-2} \cdot \mathrm{s}^{-1}$, 其峰值显著高于 3 月、6月和 12 月 $(p<0.05) ; 3$ 月益智的 $P_{\mathrm{n}}$ 呈“V”形曲线, 8:00 $P_{\mathrm{n}}$ 开始急剧下降, 14:00降到最低值, 为 -0.27 $\mu \mathrm{mol} \cdot \mathrm{m}^{-2} \cdot \mathrm{s}^{-1}$, 表明在旱季(3月) $14: 00$, 益智光合作 用受到高温胁迫, 使得Rubisco活化酶活性降低, 造
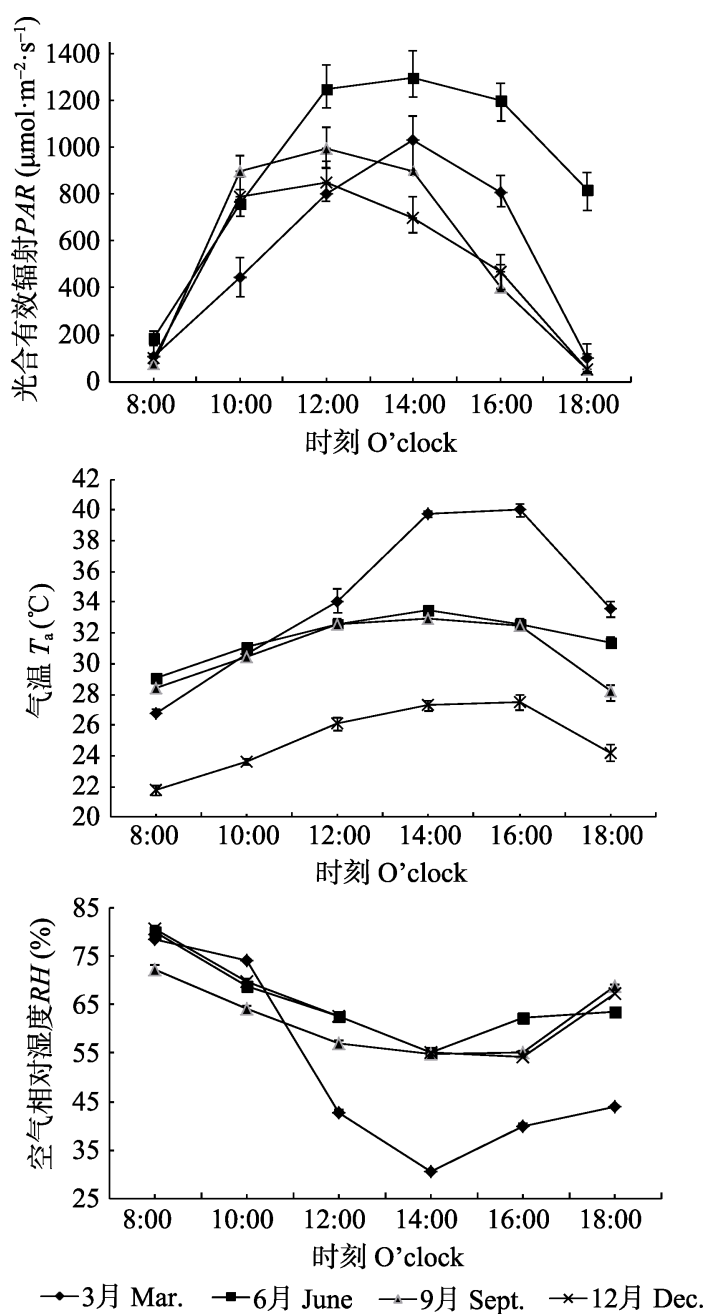

图2 橡胶林下光合有效辐射、气温和空气相对湿度日变化 (平均值土标准偏差)。

Fig. 2 Daily variations of photosynthetic active radiation $(P A R)$, air temperature $\left(T_{\mathrm{a}}\right)$, air humidity $(R H)$ under the Hevea brasiliensis forest (mean $\pm S D)$.

成叶肉光合能力下降。

胞间 $\mathrm{CO}_{2}$ 浓度 $\left(C_{\mathrm{i}}\right)$ 是光合生理研究中最重要的 一个参数。由图 3 可知, 不同季节 $C_{\mathrm{i}}$ 随着一天中环境 因子的变化, 均出现上下波动的现象; 6 月、9月和 12 月 $C_{\mathrm{i}}$ 呈“W”形曲线，分别在 10:00和14:00出现波谷; 而3月 $C_{\mathrm{i}}$ 在 $14: 00$ 急剧上升, 达到381.41 $\mathrm{mmol} \cdot \mathrm{mol}^{-1}$, 这主要是益智 $P_{\mathrm{n}}$ 受阻, 造成细胞内 $\mathrm{CO}_{2}$ 积累的结果。

\subsection{2 气孔导度和气孔阀值}

气孔导度 $\left(G_{\mathrm{s}}\right)$ 与 $P_{\mathrm{n}}$ 密切相关, 6 月、 9 月和 12 月益 智 $G_{\mathrm{s}}$ 日变化与 $P_{\mathrm{n}}$ 日变化趋势基本一致; 而 3 月 $G_{\mathrm{s}}$ 在 8:00-14:00缓慢下降到最低值, 为 $0.01 \mathrm{~mol} \cdot \mathrm{m}^{-2} \cdot \mathrm{s}^{-1}$, 14:00-18:00变化不显著, 这主要是因为 3 月干旱少 雨，土壤含水量为全年最低水平，呈现半干旱状态， 空气湿度小, 水分胁迫下降低了益智叶片的气孔开 

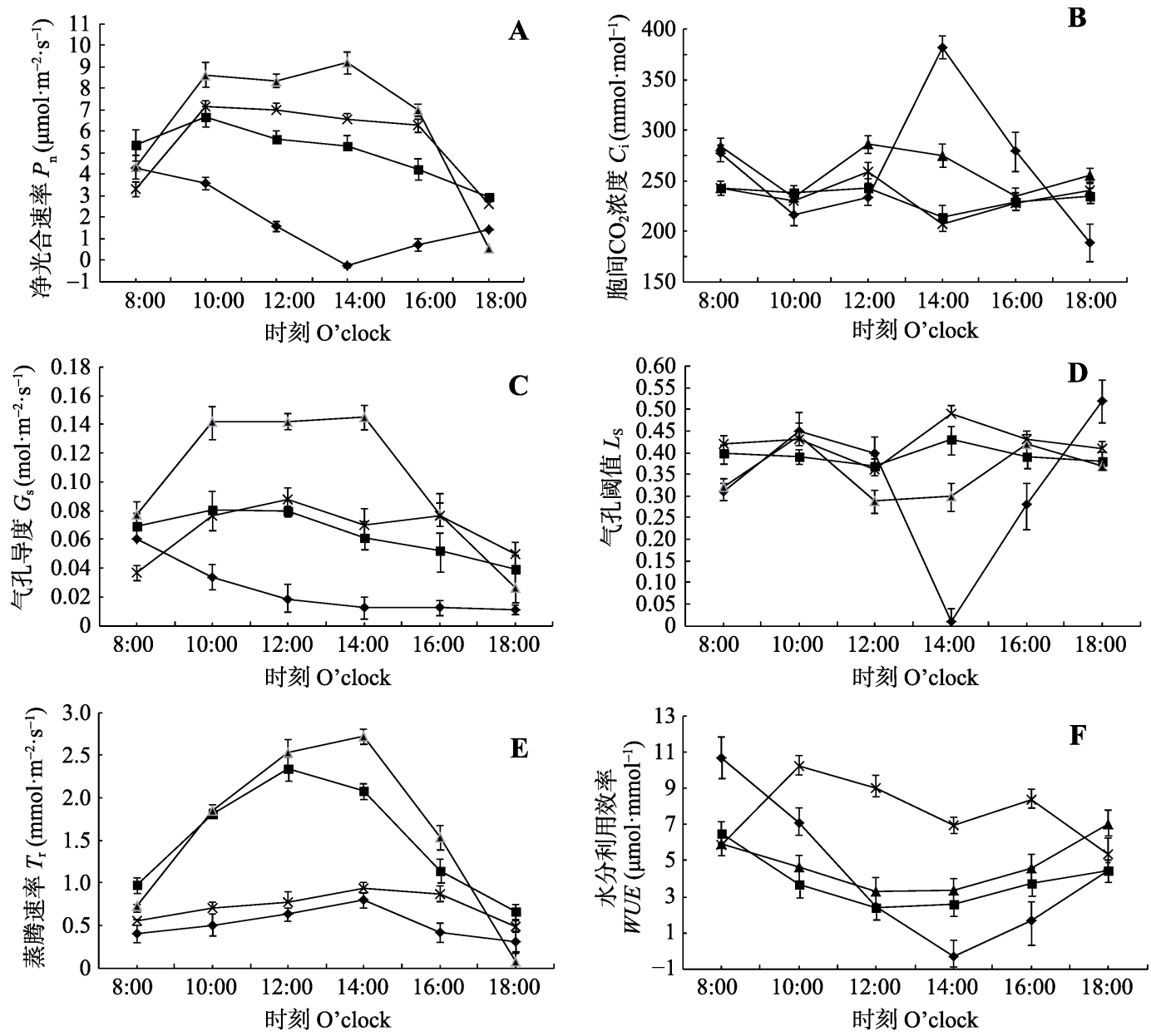

$\rightarrow 3$ 月 Mar. $\rightarrow 6$ 月 June

×9月 Spet. $\rightarrow 12$ 月 Dec.

图3 不同月份益智光合特性的日变化(平均值土标准偏差)。

Fig. 3 Diurnal changes of photosynthetic characteristics of Alpinia oxyphylla in different months (mean $\pm S D$ ). $C_{\mathrm{i}}$, intercellular $\mathrm{CO}_{2}$ concentration; $G_{\mathrm{s}}$, stomatal conductance; $L_{\mathrm{s}}$, stomatal limitation; $P_{\mathrm{n}}$, the net photosynthetic rate; $T_{\mathrm{r}}$, transpiration rate; WUE, water use efficiency.

度以降低蒸腾作用, 减少水分流失。

气孔阀值 $\left(L_{\mathrm{s}}\right)$ 和 $C_{\mathrm{i}}$ 都是分析气孔限制和非气孔 限制对光合速率影响的判断依据。由图3所示, 不同 季节 $L_{\mathrm{s}}$ 的日变化与 $C_{\mathrm{i}}$ 呈相反的趋势。

\subsection{3 蒸腾速率和水分利用率}

不同季节益智叶片的蒸腾速率 $\left(T_{\mathrm{r}}\right)$ 日变化均呈 单峰曲线, 早晨和晚上 $T_{\mathrm{r}}$ 较低, 12:00-14:00最高(图 3 )。雨季(6月和 9 月) $T_{\mathrm{r}}$ 的日平均值和日最高值均显 著高于旱季(3月和 12 月), 其中 9 月日平均值和日最 高值分别为 1.57 和 $2.72 \mathrm{mmol} \cdot \mathrm{m}^{-2} \cdot \mathrm{s}^{-1}$, 分别是早季 (12月)日平均值和日最高值的 2.18 倍和 2.89 倍。

雨季(6月和 9 月)和旱季的 3 月, 益智叶片的水分 利用效率(WUE) 呈“V”形曲线, 早晨和傍晚WUE最 高, 12:00-14:00最低, 与雨季(6月和9月)相比, 旱季 3 月 $W U E$ 下降幅度更大; 3 月 8:00 的 WUE 为 10.69 $\mu \mathrm{mol} \cdot \mathrm{mmol}^{-1}$, 比6月高4.17 $\mu \mathrm{mol} \cdot \mathrm{mmol}^{-1}, 3$ 月 $14: 00$
$W U E$ 降到 $-0.33 \mu \mathrm{mol} \cdot \mathrm{mmol}^{-1}$, 此时又比 6 月低 2.89 $\mu \mathrm{mol} \cdot \mathrm{mmol}^{-1}$, 这可能是 3 月益智遭受土壤水分胁迫 和极端高温影响, 气体交换速率减缓, 蒸滕作用和 光合作用均受到抑制的结果。其中在 3 月 14:00强光 照和低土壤水分环境下, 能观察到益智叶片短暂缺 水而蜷曲的现象, 这一形态变化与其WUE急剧下降 为负值的实验结果相吻合。

\section{3 益智叶片叶绿素含量、比叶质量和叶片含水量 季节变化特征}

从叶绿素各组分的季节变化(表1)中可看出, 3 月益智叶片的总叶绿素、叶绿素 $\mathrm{b}$ 、类胡萝卜素含量 均显著高于 6 月、 9 月和 12 月, 而叶绿素a/b显著低于 6 月、9月和 12 月 $(p<0.05)$; 叶绿素 $\mathrm{a}$ 的含量在不同季 节没有表现出显著差异 $(p>0.05)$ 。3 月益智叶片 $L M A$ 显著高于 6 月、9月和 12 月，分别高了 $16.00 \% 、 4.77 \%$ 和 $11.74 \%$ 。益智叶片含水量季节变化趋势与叶片 
表1 益智叶片光和色素含量、比叶质量和叶片含水量

Table 1 The photosynthetic pigment content, leaf mass per area (LMA) and leaf water content of Alpinia oxyphylla

\begin{tabular}{|c|c|c|c|c|c|c|c|}
\hline & $\begin{array}{c}\text { 叶绿素a } \\
\mathrm{Chl} \mathrm{a}\left(\mathrm{mg} \cdot \mathrm{cm}^{-2}\right)\end{array}$ & $\begin{array}{c}\text { 叶绿素b } \\
\mathrm{Chl} \mathrm{b}\left(\mathrm{mg} \cdot \mathrm{cm}^{-2}\right)\end{array}$ & $\begin{array}{c}\text { 类胡萝卜素 } \\
\operatorname{Car}\left(\mathrm{mg} \cdot \mathrm{cm}^{-2}\right)\end{array}$ & $\begin{array}{c}\text { 总叶绿素 } \\
\mathrm{Chl}\left(\mathrm{mg} \cdot \mathrm{cm}^{-2}\right)\end{array}$ & $\begin{array}{c}\text { 叶绿素a/b } \\
\mathrm{Chl} \mathrm{a/b}\end{array}$ & $\begin{array}{c}\text { 比叶质量 } \\
L M A\left(\mathrm{~g} \cdot \mathrm{m}^{-2}\right)\end{array}$ & $\begin{array}{c}\text { 叶片含水量 } \\
\text { Leaf water content }(\%)\end{array}$ \\
\hline 3月 Mar. & $2.60^{\mathrm{a}}$ & $1.64^{\mathrm{a}}$ & $3.15^{\mathrm{a}}$ & $7.39^{\mathrm{a}}$ & $1.59^{\mathrm{a}}$ & $51.26^{\mathrm{a}}$ & $65.17^{\mathrm{c}}$ \\
\hline 6月 June & $2.60^{\mathrm{a}}$ & $1.28^{\mathrm{b}}$ & $2.67^{\mathrm{c}}$ & $6.55^{\mathrm{b}}$ & $2.02^{\mathrm{b}}$ & $43.06^{\mathrm{c}}$ & $74.31^{\mathrm{a}}$ \\
\hline 9月 Sept. & $2.62^{\mathrm{a}}$ & $1.33^{\mathrm{b}}$ & $2.60^{\mathrm{c}}$ & $6.55^{\mathrm{b}}$ & $1.97^{\mathrm{b}}$ & $48.82^{\mathrm{ab}}$ & $75.95^{\mathrm{a}}$ \\
\hline 12月 Dec. & $2.52^{\mathrm{a}}$ & $1.31^{\mathrm{b}}$ & $2.76^{\mathrm{b}}$ & $6.48^{\mathrm{b}}$ & $1.93^{\mathrm{b}}$ & $45.25^{\mathrm{bc}}$ & $68.64^{\mathrm{b}}$ \\
\hline
\end{tabular}

不同的小写字母表示不同月份间差异显著 $(p<0.05)$ 。

Car, carotenoid; Chl, chlorophyll. Different letters indicate statistically significant differences among different months $(p<0.05)$.

$L M A$ 变化趋势相反。

\section{4 光响应曲线季节变化特征}

植物光响应曲线能反映净光合速率随光强变化 的特征, 如图4所示, 与旱季相比较, 随着 $P A R$ 的增 加，雨季益智叶片 $P_{\mathrm{n}}$ 显著增加。当 $P A R<90$ $\mu \mathrm{mol} \cdot \mathrm{m}^{-2} \cdot \mathrm{s}^{-1}$ 时, 4 个季节的益智叶片 $P_{\mathrm{n}}$ 线性递增, 光 响应曲线变化规律差异不显著; $P A R>90$ $\mu \mathrm{mol} \cdot \mathrm{m}^{-2} \cdot \mathrm{s}^{-1}$ 时, 3 月益智叶片光响应曲线拐点显著 低于6月、9月和 12 月; 当 $P A R>800 \mu \mathrm{mol} \cdot \mathrm{m}^{-2} \cdot \mathrm{s}^{-1}$ 时, 各季节的 $P_{\mathrm{n}}$ 趋于饱和状态。

由Ye (2007)的直角双曲线修正模型计算出益智 叶片各光合响应参数，如表2所示：不同季节益智 叶片 $P_{\mathrm{n} \max }$ 差异显著, 3 月 $P_{\mathrm{n} \max }$ 最小, 仅为 3.213 $\mu \mathrm{mol} \cdot \mathrm{m}^{-2} \cdot \mathrm{s}^{-1}$, 仅是 9 月 $P_{\mathrm{n} \text { max }}$ 的 $30 \% ; 4$ 个季节叶片的

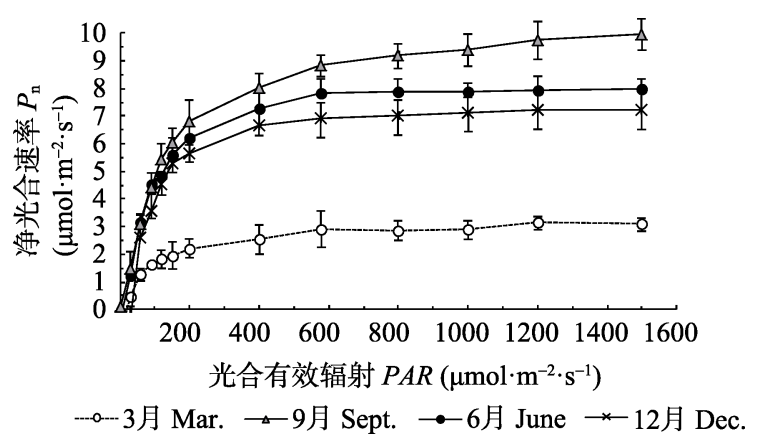

图4 不同月份益智叶片的光响应曲线(平均值土标准偏差)。

Fig. 4 Light response curves of net photosynthetic rate $\left(P_{\mathrm{n}}\right)$ in Alpinia oxyphylla in different months (mean $\pm S D)$.
$A Q E$ 大小顺序为 3 月 $<12$ 月 $<9$ 月 $<6$ 月; 3 月份叶片的 $I_{\mathrm{c}}$ 和 $R_{\mathrm{d}}$ 均显著高于 6 月、 9 月和 12 月。表明早季转入 雨季后益智叶片线粒体呼吸速率下降, 导致 $I_{\mathrm{c}}$ 降低, 进一步提升了益智植株的光合能力。

\section{5 不同季节益智净光合速率与主要生理生态因 子的关系}

由表 3 可知, 不同季节影响益智植株 $P_{\mathrm{n}}$ 的主导 因子是不同的。3月 $T_{\mathrm{a}}$ 和 $R H$ 均与 $P_{\mathrm{n}}$ 呈极显著相关关 系 $(p<0.01), C_{\mathrm{a}}$ 和 $G_{\mathrm{s}}$ 与 $P_{\mathrm{n}}$ 呈显著相关关系 $(p<0.05)$; 6月和 9 月 $G_{\mathrm{s}}$ 与 $P_{\mathrm{n}}$ 呈极显著相关关系 $(p<0.01), 9$ 月 $T_{\mathrm{a}}$ 和 $P A R$ 与 $P_{\mathrm{n}}$ 呈显著相关关系 $(p<0.05) ; 12$ 月 $P A R$ 与 $P_{\mathrm{n}}$ 呈极显著相关关系 $(p<0.01), G_{\mathrm{s}}$ 与 $P_{\mathrm{n}}$ 呈显著相关关 系 $(p<0.05)$ 。

\section{3 讨论和结论}

光合作用是植物生长发育中非常重要的生理过 程, 受环境条件的长期影响, 植物从生理到形态形 成了一系列应对环境变化的适应对策(Lewis et al., 2002)。随着季节更替，植物光合作用的影响因素如 $P A R$ 、空气温湿度及植物生理和结构因素等各方面 也在不断发生变化, 这些变化必然引起植物光合特 征随季节更替而变化。阴生植物一般光合速率偏低 (Araus \& Serret, 1986), 4 个季节益智植株 $P_{\mathrm{n}}$ 的日平 均值来看, 全年益智植株 $P_{\mathrm{n}}$ 较低, 具有喜阴性特点。 除了 3 月 $P_{\mathrm{n}}$ 日平均值仅为 $1.86 \mu \mathrm{mol} \cdot \mathrm{m}^{-2} \cdot \mathrm{s}^{-1}, 6$ 月、9月

表2 不同月份益智叶片光响应曲线特征参数

Table 2 Parameters of light response curves of Alpinia oxyphylla in different months

\begin{tabular}{|c|c|c|c|c|c|}
\hline 月份 Month & 表观量子效率 $A Q E$ & $\begin{array}{c}\text { 光补偿点 } \\
I_{\mathrm{c}}\left(\mu \mathrm{mol} \cdot \mathrm{m}^{-2} \cdot \mathrm{s}^{-1}\right)\end{array}$ & $\begin{array}{c}\text { 暗呼吸速率 } \\
R_{\mathrm{d}}\left(\mu \mathrm{mol} \cdot \mathrm{mol}^{-1}\right)\end{array}$ & $\begin{array}{c}\text { 最大净光合速率 } \\
P_{\mathrm{nmax}}\left(\mu \mathrm{mol} \cdot \mathrm{m}^{-2} \cdot \mathrm{s}^{-1}\right)\end{array}$ & $\begin{array}{c}\text { 光饱和点 } \\
I_{\mathrm{s}}\left(\mu \mathrm{mol} \cdot \mathrm{m}^{-2} \cdot \mathrm{s}^{-1}\right)\end{array}$ \\
\hline 3月 Mar. & $0.068^{\mathrm{c}}$ & $16.144^{\mathrm{a}}$ & $0.865^{\mathrm{a}}$ & $3.213^{\mathrm{d}}$ & $522.968^{\mathrm{b}}$ \\
\hline 6月 June & $0.100^{\mathrm{a}}$ & $5.813^{\mathrm{b}}$ & $0.550^{\mathrm{b}}$ & $8.006^{\mathrm{c}}$ & $1010.264^{\mathrm{a}}$ \\
\hline 9月 Sept. & $0.095^{\mathrm{a}}$ & $3.514^{\mathrm{c}}$ & $0.324^{\mathrm{c}}$ & $10.648^{\mathrm{a}}$ & $1021.726^{\mathrm{a}}$ \\
\hline 12月 Dec. & $0.086^{\mathrm{b}}$ & $3.906^{\mathrm{c}}$ & $0.326^{\mathrm{c}}$ & $8.783^{\mathrm{b}}$ & $964.900^{\mathrm{a}}$ \\
\hline
\end{tabular}

不同的小写字母表示不同月份间差异显著 $(p<0.05)$ 。

$A Q E$, apparent quantum yield; $I_{\mathrm{c}}$, light compensation point; $I_{\mathrm{s}}$, light saturation point; $P_{\mathrm{nmax}}$, maximum net photosynthetic rate; $R_{\mathrm{d}}$, dark respiration rate. Different letters indicate statistically significant differences among different months $(p<0.05)$.

www.plant-ecology.com 
表3＼cjkstart不同月份净光合速率 $\left(P_{\mathrm{n}}\right)$ 与主要生理生态因子的相关系数

Table 3 The correlation analysis between net photosynthetic rate $\left(P_{\mathrm{n}}\right)$ of Alpinia oxyphylla and the main environmental factors in different months

\begin{tabular}{|c|c|c|c|c|c|c|c|c|c|}
\hline 月份 & Month & $\begin{array}{c}\text { 生理生态因子 } \\
\text { Physio-ecological factors }\end{array}$ & $P_{\mathrm{n}}$ & $C_{\mathrm{a}}$ & $P A R$ & $T_{\mathrm{a}}$ & $R H$ & $G_{\mathrm{s}}$ & $C_{\mathrm{i}}$ \\
\hline \multirow[t]{7}{*}{ 3月 } & Mar. & $P_{\mathrm{n}}$ & 1.000 & & & & & & \\
\hline & & $C_{\mathrm{a}}$ & $0.883^{*}$ & 1.000 & & & & & \\
\hline & & $P A R$ & -0.678 & -0.664 & 1.000 & & & & \\
\hline & & $T_{\mathrm{a}}$ & $-0.947^{* *}$ & $-0.889^{*}$ & 0.735 & 1.000 & & & \\
\hline & & $R H$ & $0.985^{* *}$ & $0.847^{*}$ & -0.669 & $-0.902^{*}$ & 1.000 & & \\
\hline & & $G_{\mathrm{s}}$ & $0.891^{*}$ & $0.946^{* *}$ & -0.539 & $-0.852^{*}$ & $0.898^{*}$ & 1.000 & \\
\hline & & $C_{\mathrm{i}}$ & -0.464 & -0.234 & 0.554 & 0.488 & -0.372 & -0.044 & 1.000 \\
\hline \multirow[t]{7}{*}{ 6月 } & June & $P_{\mathrm{n}}$ & 1.000 & & & & & & \\
\hline & & $C_{\mathrm{a}}$ & 0.692 & 1.000 & & & & & \\
\hline & & $P A R$ & -0.349 & $-0.868^{*}$ & 1.000 & & & & \\
\hline & & $T_{\mathrm{a}}$ & -0.265 & -0.793 & $0.937^{* *}$ & 1.000 & & & \\
\hline & & $R H$ & 0.449 & $0.909^{*}$ & $-0.904^{*}$ & $-0.950^{* *}$ & 1.000 & & \\
\hline & & $G_{\mathrm{s}}$ & $0.921^{* *}$ & 0.507 & -0.108 & -0.099 & 0.279 & 1.000 & \\
\hline & & $C_{\mathrm{i}}$ & 0.283 & 0.576 & -0.494 & -0.702 & 0.729 & 0.403 & 1.000 \\
\hline \multirow[t]{7}{*}{ 9月 } & Sept. & $P_{\mathrm{n}}$ & 1.000 & & & & & & \\
\hline & & $C_{\mathrm{a}}$ & -0.416 & 1.000 & & & & & \\
\hline & & $P A R$ & $0.908^{*}$ & -0.472 & 1.000 & & & & \\
\hline & & $T_{\mathrm{a}}$ & $0.821^{*}$ & -0.665 & 0.733 & 1.000 & & & \\
\hline & & $R H$ & -0.716 & $0.837^{*}$ & -0.678 & $-0.960^{* *}$ & 1.000 & & \\
\hline & & $G_{\mathrm{s}}$ & $0.940^{* *}$ & -0.310 & $0.941^{* *}$ & 0.665 & -0.549 & 1.000 & \\
\hline & & $C_{\mathrm{i}}$ & -0.009 & -0.037 & -0.055 & -0.067 & 0.112 & 0.174 & 1.000 \\
\hline \multirow[t]{7}{*}{ 12月 } & Dec. & $P_{\mathrm{n}}$ & 1.000 & & & & & & \\
\hline & & $C_{\mathrm{a}}$ & -0.536 & 1.000 & & & & & \\
\hline & & $P A R$ & $0.969^{* *}$ & -0.470 & 1.000 & & & & \\
\hline & & $T_{\mathrm{a}}$ & 0.579 & $-0.878^{*}$ & 0.507 & 1.000 & & & \\
\hline & & $R H$ & -0.561 & $0.928^{* *}$ & -0.483 & $-0.989^{* *}$ & 1.000 & & \\
\hline & & $G_{\mathrm{s}}$ & $0.908^{*}$ & -0.737 & $0.902^{*}$ & 0.706 & -0.693 & 1.000 & \\
\hline & & $C_{\mathrm{i}}$ & -0.232 & 0.350 & -0.133 & -0.389 & 0.459 & -0.022 & 1.000 \\
\hline
\end{tabular}

$C_{\mathrm{a}}$, 环境 $\mathrm{CO}_{2}$ 浓度; $C_{\mathrm{i}}$, 胞间 $\mathrm{CO}_{2}$ 浓度; $G_{\mathrm{s}}$, 气孔导度; $P A R$, 光合有效辐射; $R H$, 空气湿度; $T_{\mathrm{a}}$, 气温。

$C_{\mathrm{a}}$, ambient $\mathrm{CO}_{2}$ concentration; $C_{\mathrm{i}}$, intercellular $\mathrm{CO}_{2}$ concentration; $G_{\mathrm{s}}$, stomatal conductance; $P A R$, photosynthetic active radiation; $R H$, air humidity; $T_{\mathrm{a}}$, air temperature. ${ }^{*}, p<0.05 ; * *, p<0.01$.

和12月的 $P_{\mathrm{n}}$ 日平均值在 $5.18-6.33 \mu \mathrm{mol} \cdot \mathrm{m}^{-2} \cdot \mathrm{s}^{-1}$ 之间, 表明在雨季旱季更替下, 益智光合生理受到环境因 子的显著影响。其中3月降水量极少，造成土壤水分 亏缺和空气湿度较低, 水分胁迫造成 $G_{\mathrm{s}}$ 降低, 导致3 月全天益智叶片 $P_{\mathrm{n}}$ 处于极低的水平。在全天大部分 时间里, 水分胁迫引起的 $G_{\mathrm{s}}$ 降低是低 $P_{\mathrm{n}}$ 的主导因子 (许大全, 1997); 水分胁迫下除了气孔因素导致光合 作用受抑制，高温也是光合抑制的非气孔因素之一， 当环境温度高于 $35{ }^{\circ} \mathrm{C}$ 时, $\mathrm{CO}_{2}$ 同化、 $\mathrm{O}_{2}$ 释放和光合 磷酸化均遭受抑制(Lewis et al., 1999), 其中Rubisco 活化酶是叶片的光合潜力主要限制酶 (CraftsBrandner \& Salvucc, 2000), 3月, 14:00-16:00气温高
达 $40.6{ }^{\circ} \mathrm{C}$, 受高温影响 $P_{\mathrm{n}}$ 降为负值, $C_{\mathrm{i}}$ 却显著增高 并达到全天的最大值(图3)，根据非气孔限制理论及 其判别依据(郑义新等, 1995)，高温导致叶片叶肉细 胞光合相关酶活性降低，此时高温胁迫是光合碳同 化受抑制的主导因子。6月、9月和12月的PAR、 $P_{\mathrm{n}}$ 和 $G_{\mathrm{s}}$ 日变化趋势基本一致(图2, 图3), 相关性分析 结果显示 9 月 $P A R$ 与 $P_{\mathrm{n}}$ 呈显著相关关系，12月为极显 著相关关系(表3), 即 9 月和 12 月 $P A R$ 是益智光合作 用的限制因子。为什么旱季的 12 月水分不是益智光 合作用的限制因子呢? 这主要是因为虽然旱季的 12 月降水量小, 土壤含水量偏低(轻度干旱)(图1), 但 是12月有数量可观的雾降水补充(庞家平等, 2009), 
缓解了土壤水分的不足, 因此益智生长和光合作用 未受到水分的胁迫, 所以 12 月水分没有成为益智光 合作用的限制因子。6月为旱季向雨季的过渡期, 这 个时期的环境因子与 $P_{\mathrm{n}}$ 无相关性, 而 $G_{\mathrm{s}}$ 与 $P_{\mathrm{n}}$ 极显著 相关(表3), 这个现象的机理有待进一步探讨。

结合林下PAR季节变化(图1)发现, 旱季(3月)林 下PAR较低, 促使益智增加叶绿素 $\mathrm{b}$ 的含量, 降低叶 绿素 $\mathrm{a} / \mathrm{b}$ 比值, 增强耐阴性, 以适应季节变化引起的 低光环境。植物叶绿素各组分含量差异可用来表征 叶片吸收太阳辐射的变化, 各种功能色素组分比值 的变化, 也反映植物适应不同光环境的光合生理策 略(Richardson et al., 2002)。叶绿素a含量决定植物的 光合效率和能力, 叶绿素 $\mathrm{b}$ 在调控光合机构天线大 小、维持其稳定性和提高其适应性中都起着重要作 用。由表 1 可知, 3 月益智叶片叶绿素 $\mathrm{b}$ 含量高于 6 月、 9月和12月, 结合林下 $P A R$ 季节变化(图1)发现, 旱季 (3月)林下 $P A R$ 较低, 促使益智增加叶绿素 $\mathrm{b}$ 的含量, 调控光合机构天线的大小, 提高光合机构对林下 $P A R$ 的敏感性, 增强耐阴能力, 以适应季节变化引 起的低光环境(Satoh et al., 2001)。LMA是表征植物 生长过程中碳同化策略的关键叶性状指标(Wright et al., 2002)。大多数研究发现环境中光照越弱、叶 片越薄、单位面积干质量越小, 比叶面积越大(左端 阳等, 2014)。本研究中 3 月的 $L M A$ 显著高于 6 月和 9 月, 这主要与橡胶树叶片物候期密切相关。3月橡胶 树处于落叶期, 橡胶林叶面积指数较低、林下透光 率高(吴志祥等, 2013); 同时3月极端高温天气和土 壤水分亏缺, 在逆境环境下植物通过提高 $L M A$ 减少 光抑制、增加水分利用效率(徐飞等, 2010)。

光响应曲线中的 $A Q E 、 I_{\mathrm{c}} 、 I_{\mathrm{s}} 、 R_{\mathrm{d}}$ 等参数能反映 环境条件及植物自身生理状况对光合作用的影响 (Ogren, 1993)。植物 $I_{\mathrm{c}}$ 和 $I_{\mathrm{s}}$ 的高低直接反映了植物对 弱光的利用能力, 是植物耐阴性评价的重要指标 (王建华等, 2011)。6-12月益智叶片的 $I_{\mathrm{s}}$ 为968-1 023 $\mu \mathrm{mol} \cdot \mathrm{m}^{-2} \cdot \mathrm{s}^{-1}$, 而大多数 $\mathrm{C}_{3}$ 阳生植物饱和光强在 $1000 \mu \mathrm{mol} \cdot \mathrm{m}^{-2} \cdot \mathrm{s}^{-1}$ 左右, 即益智表现出阳生植物的 特性; 6 月、 9 月和 12 月益智 $I_{\mathrm{c}}$ 为 $3.5-5.8 \mu \mathrm{mol} \cdot \mathrm{m}^{-2} \cdot \mathrm{s}^{-1}$, 具有极强的弱光利用能力而表现出极强的耐阴性 (朱延姝等, 2010)。由此可知益智具有较强的利用弱 光(漫射光、散射光、透射光)的能力, 其耐阴能力较 强且光环境适应幅度较宽。3月时, 受到土壤水分亏 缺的影响, AQE、 $P_{\mathrm{nmax}}$ 显著低于其他 3 个月份(表2),
有研究表明干旱胁迫或者盐胁迫条件会导致植物 $A Q Y$ 的降低(Xia et al., 2011; Lin et al., 2015), 光能 利用效率降低。其机理是植物体水分亏缺导致光合 相关酶活性降低, 引起光合作用产生非竞争性抑制 (Lin et al., 2015), 使 $P_{\mathrm{n}}$ 下降并随 $P A R$ 的变化而光响 应曲线拐点前移(图4), 从而导致 $A Q E 、 P_{\mathrm{n} \max }$ 降低, 表现出光抑制现象。

综上所述, 益智属于典型的耐阴植物, 且能适 应透光率较高的强光环境, 益智在不同季节环境因 子变化下表现出不同的光能利用策略。在雨季的 9 月和旱季的 12 月, $P A R$ 是益智光合作用的主要影响 因子; 在旱季的 3 月降水量低造成土壤水分含量不 足是益智光合作用的主要限制生态因子, 中午高温 和低空气湿度的环境因子是益智光合日变化出现 “午休现象”的主要诱导因素。因此在生产实践中, 旱季时尤其是 3 月橡胶-益智间作体系应适当开展设 施灌溉, 提高土壤含水率, 同时对土壤表面实施盖 草措施以减少土壤水分的蒸发, 缓解土壤干旱状态, 保障益智植株正常的生长和光合作用。

致谢 感谢中国热带农业科学院基本科研业务费专 项资金(17CXTD-04、NO.1630042017028、NO.2017hzs1J021)资助。

\section{参考文献}

Araus JL, Serret MD (1986). Relationships between photosynthetic capacity and leaf structure in several shade plants. American Journal of Botany, 73, 1760-1770.

Chen XM, Chen HL, Li WG, Liu SJ (2016). Remote sensing monitoring of spring phenophase of natural rubber forest in Hainan Province. Chinese Journal of Agrometeorology, 37, 111-116. [陈小敏, 陈汇林, 李伟光, 刘少军 (2016). 海南岛天然橡胶林春季物候期的遥感监测. 中国农业 气象, 37, 111-116.]

Cheng HT, Liu JK, Yan TL, Zhang QY, Wang JC (2017). Effects of different picking on seed quality of medicinal plants Alpinia oxyphylla Miq. Chinese Journal of Tropical Crops, 38，1840-1845. [程汉亭, 刘景坤, 严廷良, 张俏 燕, 王进闯 (2017). 不同采收期对药用植物——益智种 子质量的影响研究. 热带作物学报, 38, 1840-1845.]

Cheng HT, Wang JC, Hou XW, Li QF, Zou YK, Li GY, Wang DM (2015). Development status of the private rubber industry in Changjiang under a situation of rubber price downturn. Chinese Journal of Tropical Agriculture, 35(5), 78-81. [程汉亭, 王进闯, 侯宪文, 李勤奋, 邹雨坤, 李 光义, 王定美 (2015). 胶价低迷背景下昌江县民营橡胶 产业的发展现状和对策. 热带农业科学, 35(5), 78-81.] 
Crafts-Brandner SJ, Salvucci ME (2000). Rubisco activase constrains the photosynthetic potential of leaves at high temperature and $\mathrm{CO}_{2}$. Proceedings of the National Academy of Sciences of the United States of America, 97, 13430-13435.

Dossa EL, Fernandes ECM, Reid WS, Ezui K (2008). Aboveand belowground biomass, nutrient and carbon stocks contrasting an open-grown and a shaded coffee plantation. Agroforestry Systems, 72, 103-115.

Lewis JD, Lucash M, Olszyk D, Tingey DT (2002). Seasonal patterns of photosynthesis in Douglas fir seedlings during the third and fourth year of exposure to elevated $\mathrm{CO}_{2}$ and temperature. Plant, Cell \& Environment, 25, 1411-1421.

Lewis JD, Olszyk D, Tingey DT (1999). Seasonal patterns of photosynthetic light response in Douglas-fir seedlings subjected to elevated atmospheric $\mathrm{CO}_{2}$ and temperature. Tree Physiology, 19, 243-252.

Lichtenthaler HK, Wellburn AR (1983). Determination of total carotenoids and chlorophylls a and $\mathrm{b}$ of leaf in different solvents. Biochemical Society Transactions, 11, 591-592.

Lin M, Wang Z, He L, Xu K, Cheng D, Wang G (2015). Plant photosynthesis-irradiance curve responses to pollution show non-competitive inhibited Michaelis kinetics. PLOS ONE, 10, e142712. DOI: 10.1371/journal.pone.0142712.

Mcneely JA, Schroth G (2006). Agroforestry and biodiversity conservation-traditional practices, present dynamics, and lessons for the future. Biodiversity \& Conservation, 15, $549-554$.

Muthuri CW, Ong CK, Craigon J, Mati BM, Ngumi VW, Black CR (2009). Gas exchange and water use efficiency of trees and maize in agroforestry systems in semi-arid Kenya. Agriculture Ecosystems \& Environment, 129, 497-507.

Nair VD, Graetz DA (2004). Agroforestry as an approach to minimizing nutrient loss from heavily fertilized soils: The Florida experience. Agroforestry Systems, 61, 269-279.

Ogren E (1993). Convexity of the photosynthetic light-response curve in relation to intensity and direction of light during growth. Plant Physiology, 101, 1013-1019.

Ogwuche P, Umar HY, Esekhade TU, Francis SY (2012). Economies of intercropping natural rubber with arable crops: A panacea for poverty alleviation of rubber farmers. Journal of Agriculture \& Social Sciences, 8(3), 100-102.

Pang JP, Chen MY, Tang JW, Guo XM, Zeng R (2009). The dynamics of plant growth and soil moisture and nutrient in the rubber plantation and rubber-Flemingia macrophylla agroforestry. Journal of Mountain Science, 27, 433-441. [庞家平, 陈明勇, 唐建维, 郭贤明, 曾荣 (2009). 橡胶大叶千斤拔复合生态系统中的植物生长与土壤水分养 分动态. 山地学报, 27, 433-441.]

Qi DL, Sun R, Xie GS, Yang C, Chen BQ, Lan GY, Tao ZL, Yang XB, Wu ZX (2017). A preliminary study on seasonal changes of soil moisture in rubber plantation of low tapping years and its responses to meteorological factors in Western Hainan Island, China. Ecological Science, 36(6), 44-48. [祁栋灵, 孙瑞, 谢贵水, 杨川, 陈帮乾, 兰国玉, 陶忠良, 杨小波, 吴志祥 (2017). 海南西部低割龄橡胶 林土壤水分季节变化特征及其对气象因子响应研究初 报. 生态科学, 36(6), 44-48.]

Richardson AD, Duigan SP, Berlyn GP (2002). An evaluation of noninvasive methods to estimate foliar chlorophyll content. New Phytologist, 153, 185-194.

Righi CA, Bernardes MS, Lunz AMP, Pereira CR, Neto DD, Favarin JL (2007). Measurement and simulation of solar radiation availability in relation to the growth of coffee plants in an agroforestry system with rubber trees. Revista Árvore, 31, 195-207.

Righi CA, Lunz AMP, Bernardes MS, Pereira CR, Teramoto ER, Favarin JL (2008). Coffee water use in agroforestry system with rubber trees. Revista Árvore, 32, 781-792.

Satoh S, Ikeuchi M, Mimuro M, Tanaka A (2001). Chlorophyll $\mathrm{b}$ expressed in cyanobacteria functions as a light-harvesting antenna in photosystem I through flexibility of the proteins. Journal of Biological Chemistry, 276, 4293-4297.

Shen SG, Zheng Z (2008). Photosynthesis characteristics and impact factors of Camellia sinensis leaves in rubber-tea community in Xishuangbanna, China. Chinese Journal of Applied and Environmental Biology, 14, 32-37. [沈守艮, 郑征 (2008). 西双版纳胶-茶群落中茶树的光合特性及 其影响因子. 应用与环境生物学报, 14, 32-37.]

Tuittila ES, Vasander H, Laine J (2004). Sensitivity of C sequestration in reintroduced Sphagnum to water-level variation in a cutaway peatland. Restoration Ecology, 12, 483-493.

Wang JH, Ren SF, Shi BS, Liu BX, Zhou YL (2011). Effects of shades on the photosynthetic characteristics and chlorophyll fluorescence parameters of Forsythia suspensa. Acta Ecologica Sinica, 31, 1811-1817. [王建华, 任士福, 史宝 胜, 刘炳响, 周玉丽 (2011). 遮荫对连翘光合特性和叶 绿素荧光参数的影响. 生态学报, 31, 1811-1817.]

Wright IJ, Westoby M, Reich PB (2002). Convergence towards higher leaf mass per area in dry and nutrient-poor habitats has different consequences for leaf life span. Journal of Ecology, 90, 534-543.

Wu ZX, Du LY, Xie GS, Lan GY, Chen BQ, Zhou ZD (2013). Spatiotemporal distribution of photosynthetically active radiation in rubber plantations in Hainan Island. Journal of Northwest Forestry University, 28(3), 13-21. [ 吴志祥, 杜 莲英, 谢贵水, 兰国玉, 陈帮乾, 周兆德 (2013). 海南 岛橡胶林光合有效辐射的时空分布. 西北林学院学报, 28(3), 13-21.]

Xia JB, Zhang SY, Zhang GC, Xie WJ, Lu ZH (2011). Critical responses of photosynthetic efficiency in Campsis radicans (L.) Seem to soil water and light intensities. African Journal of Biotechnology, 10, 17748-17754. 
Xu DQ (1997). Some problems in stomatal limitation analysis of photosynthesis. Plant Physiology Communications, 33, 241-244. [许大全 (1997). 光合作用气孔限制分析中的 一些问题. 植物生理学通讯, 33, 241-244.]

Xu F, Guo WH, Xu WH, Wang RQ (2010). Effects of light intensity on growth and photosynthesis of seedlings of Quercus acutissima and Robinia pseudoacacia. Acta Ecologica Sinica, 30，3098-3107. [徐飞, 郭卫华, 徐伟 红, 王仁卿 (2010). 不同光环境对麻栎和刺槐幼苗生长 和光合特征的影响. 生态学报, 30, 3098-3107.]

Ye ZP (2007). A new model for relationship between irradiance and the rate of photosynthesis in Oryza sativa. Photosynthetica, 45, 637-640.

Zhang B, Zhang TL (1997). Hydraulic ecological characteristics of alley cropping systems and its productivity in low hilly red soil region. Chinese Journal of Ecology, 16(4), 1-5. [张斌, 张桃林 (1997). 低丘红壤区农林间作系统 的水分生态特征及生产力. 生态学杂志, 16(4), 1-5.]

Zheng YX, Zang JY, Lin Y (1995). The photosynthetic stomatal and nonstomatal limitation of plant leaves under water stress. Plant Physiology Communications, 31, 293-297. [郑义新, 藏俊英, 林艳 (1995). 水分胁迫下 植物叶片光合的气孔和非气孔限制. 植物生理学通讯, 31, 293-297.]

Zhu YS, Fan JJ, Feng H (2010). Effects of low light on photosynthetic characteristics of tomato at different growth stages. Chinese Journal of Applied Ecology, 21, 3141-3146. [朱延姝, 樊金娟, 冯辉 (2010). 弱光胁迫 对不同生育期番茄光合特性的影响. 应用生态学报, 21, 3141-3146.]

Zuo DY, Kuang SB, Zhang GH, Long GQ, Meng ZG, Chen ZJ, Wei FG, Yang SC, Chen JW (2014). Eco-physiological adaptation of Panax notoginseng to different light intensity. Journal of Yunnan Agricultural University, 29, 521-527. [左端阳, 匡双便, 张广辉, 龙光强, 孟珍贵, 陈中坚, 魏富刚, 杨生超, 陈军文 (2014). 三七(Panax notoginseng)对不同光照强度的生理生态适应性研究. 云南农业大学学报(自然科学), 29, 521-527.]

责任编委: 王根轩 责任编辑: 李 敏 